\title{
Typical lesions in the fetal nervous system: correlations between fetal magnetic resonance imaging and obstetric ultrasonography findings
}

\author{
Heron Werner', Taisa Davaus Gasparetto', Pedro Daltro', Emerson Leandro Gasparetto', \\ Edward Araujo Júnior ${ }^{2}$
}

'Department of Radiology, Clínica de Diagnóstico por Imagem (CDPI), Rio de Janeiro; ${ }^{2}$ Department of Obstetrics, Paulista School of Medicine, Federal University of São Paulo (EPM-UNIFESP), São Paulo, Brazil

Central nervous system (CNS) malformations play a role in all fetal malformations. Ultrasonography (US) is the best screening method for identifying fetal CNS malformations. A good echographic study depends on several factors, such as positioning, fetal mobility and growth, the volume of amniotic fluid, the position of the placenta, the maternal wall, the quality of the apparatus, and the sonographer's experience. Although US is the modality of choice for routine prenatal follow-up because of its low cost, wide availability, safety, good sensitivity, and real-time capability, magnetic resonance imaging (MRI) is promising for the morphological evaluation of fetuses that otherwise would not be appropriately evaluated using US. The aim of this article is to present correlations of fetal MRI findings with US findings for the major CNS malformations.

Keywords: Fetus; Central nervous system; Ultrasound; Magnetic resonance imaging

\section{Introduction}

Fetal imaging evaluation has improved over the years. Faced with more complex diagnoses, magnetic resonance imaging (MRI) has become widely used as an important complement to prenatal ultrasonography (US). Due to its higher contrast resolution than US, fetal MRI allows normal versus abnormal tissue to be better differentiated, providing detailed imaging information on fetal structures, particularly the brain. To date, fetal MRI has been shown to play an important role in the evaluation of structural brain development and in the assessment of abnormalities suspected on US $[1,2]$. Moreover, the use of fetal MRI has been shown to help in counseling parents during pregnancy and in discussions about treatment [1].

As the indications for fetal brain MRI are mainly based on abnormal US findings, fetal MRI is usually performed during the second half of gestation, from 18 to 20 weeks onward. After that point, the utility of prenatal US is limited due to decreased amniotic fluid volume, fetal positioning, and

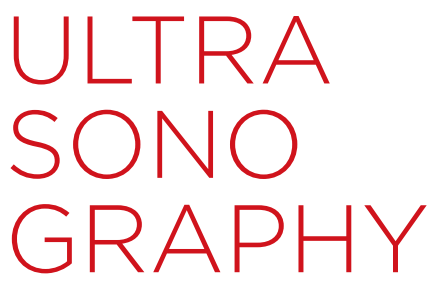

PICTORIAL ESSAY

https://doi.org/10.14366/usg. 17040 pISSN: 2288-5919 e elSSN: 2288-5943 Ultrasonography 2018;37:261-274

Received: May 29, 2017

Revised: October 21, 2017

Accepted: October 21, 2017

Correspondence to:

Edward Araujo Júnior, PhD, Department of Obstetrics, Paulista School of Medicine, Federal University of São Paulo (EPM-UNIFESP), Rua Belchior de Azevedo, 156 apto. 111 Torre Vitoria, São Paulo, CEP 05089-030, Brazil

Tel. $+55-11-37965944$

Fax. +55-11-37965944

E-mail: araujojred@terra.com.br

This is an Open Access article distributed under the terms of the Creative Commons Attribution NonCommercial License (http://creativecommons.org/ licenses/by-nc/3.0/) which permits unrestricted noncommercial use, distribution, and reproduction in any medium, provided the original work is properly cited.

Copyright (? 2018 Korean Society of Ultrasound in Medicine (KSUM)

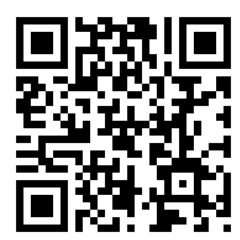

How to cite this article:

Werner H, Gasparetto TD, Daltro P, Gasparetto $E L$, Araujo Júnior $E$. Typical lesions in the fetal nervous system: correlations between fetal magnetic resonance imaging and obstetric ultrasonography findings. Ultrasonography. 2018 Jul;37(3):261-274. 
acoustic shadowing from the ossifying calvaria. For these reasons, MRI represents an important modality for morphologic evaluation of the fetal brain in the second half of gestation $[1,3]$.

The most common indications for imaging the fetal brain are briefly discussed below, and include anencephaly, ventriculomegaly, corpus callosum agenesis, holoprosencephaly, hydranencephaly, schizencephaly, porencephaly, microcephaly, Chiari malformation, iniencephaly, the Dandy-Walker malformation, vein of Galen malformations, tuberous sclerosis, and encephalocele.

\section{Imaging}

Fetal MRI is routinely performed using 1.5-T or 3.0-T MRI scanners [3]. Conventional T1- and T2-weighted images are obtained in the sagittal, coronal, and axial planes relative to the fetal head [2]. T2weighted sequences are useful for evaluating the anatomy and the sulcation pattern of the central nervous system (CNS), while T1-weighted sequences are valuable for assessing the presence of bleeding and myelination [4].

Even with rapid image acquisition, fetal motion can still affect the quality of the results, as high spatial and temporal resolution is required. Problems related to movement and technical scanning issues, due to the small region to be imaged and interference from the surrounding uterine environment, have limited the ability of advanced imaging techniques to provide reliable information on the brain $[2,5,6]$. For these reasons, advanced techniques such as diffusion tensor imaging, proton magnetic resonance spectroscopy, and functional MRI are not widely used for fetal imaging in routine clinical practice $[2,3,5]$.

\section{Defects of the Brain and CNS}

\section{Anencephaly}

Anencephaly refers to a defect in the closure of the anterior neural tube, with an overall incidence of approximately 1 in 1,000 births and a lethal prognosis [7]. Anencephaly is characterized by the absence of the cranial vault, resulting in the exposure of neural tissue. An early diagnosis can be easily made with US in the first trimester (Fig. 1). However, MRI can help in cases of multiple gestations, in which the assessment of the affected fetus is impaired. An addition, fetal MRI may provide benefits for parental counseling and management decisions $[8,9]$.

\section{Ventriculomegaly}

Ventriculomegaly is one of the most frequent abnormal brain findings. It is related to an imbalance between the production and reabsorption of cerebrospinal fluid, leading to an excess of cerebral fluid. As a result, the lateral ventricles may show different degrees of enlargement, which may or may not be associated with dilatation of the third and fourth ventricles. Indeed, the term ventriculomegaly is only used when the width of one or both ventricles, measured at the level of the glomus of the choroid plexus (atrium), is $\geq 10 \mathrm{~mm}$ at any stage of pregnancy $[10,11]$.

In cases of US-detected ventriculomegaly, fetal MRI is useful for assessing brain parenchyma that may be compromised, as well as for evaluating associated malformations, especially those related to the CNS (Fig. 2). Associations with other anomalies occur in approximately $70 \%-85 \%$ of cases, including myelomeningocele (30\%) and brain injuries such as agenesis of the corpus callosum, cortical malformations, periventricular heterotopia, cerebellar malformations, hemimegalencephaly, periventricular white matter

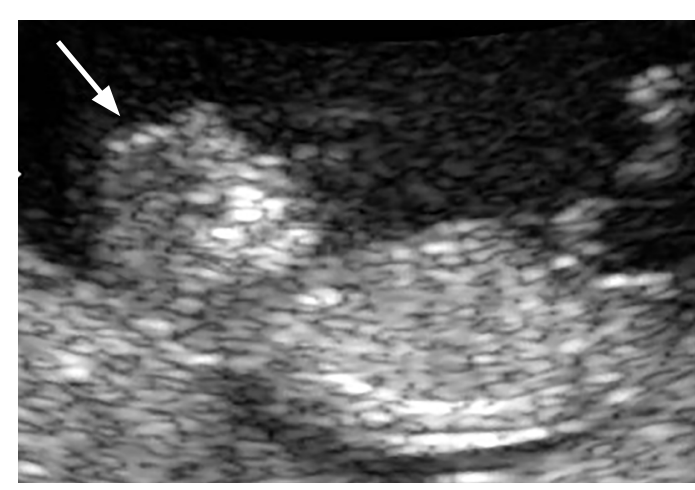

A

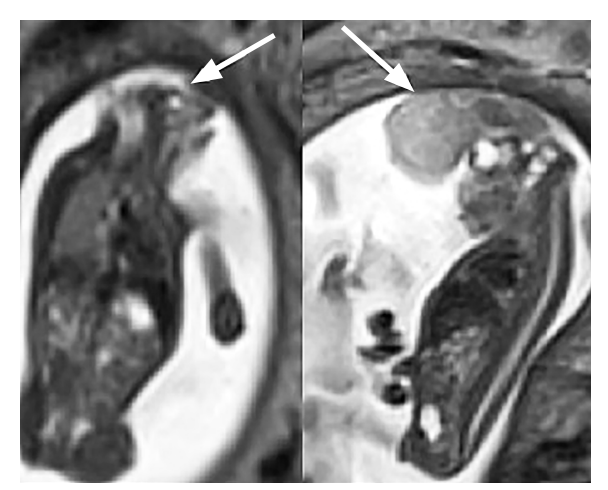

B

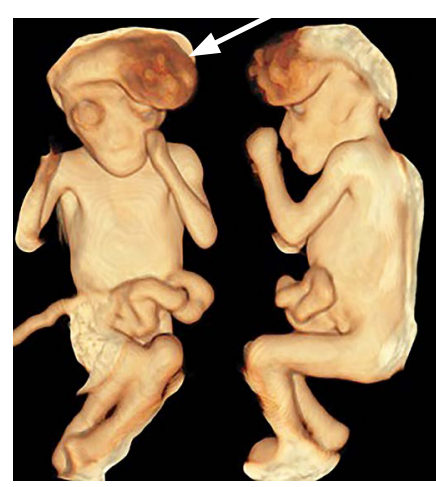

C

Fig. 1. Fetus at 13 weeks with exencephaly.

A. Sagittal ultrasonography shows flat head (arrow). B, C. Coronal (left) and sagittal (right) T2-weighted images (B) and 3-dimensional reconstruction images of magnetic resonance imaging show the dysmorphic brain tissue free in the amniotic cavity (arrows). 
injury, porencephaly, multicystic encephalomalacia, intraventricular hemorrhage, and germinal matrix hemorrhage [12]. Moreover, defects involving the heart, thorax, kidneys, abdominal wall, face, and extremities may be observed. However, in some cases, ventriculomegaly is the only abnormal finding, which is referred to as isolated ventriculomegaly. In such cases, the risk of aneuploidy may be higher, and a more specific analysis is necessary (Fig. 3).

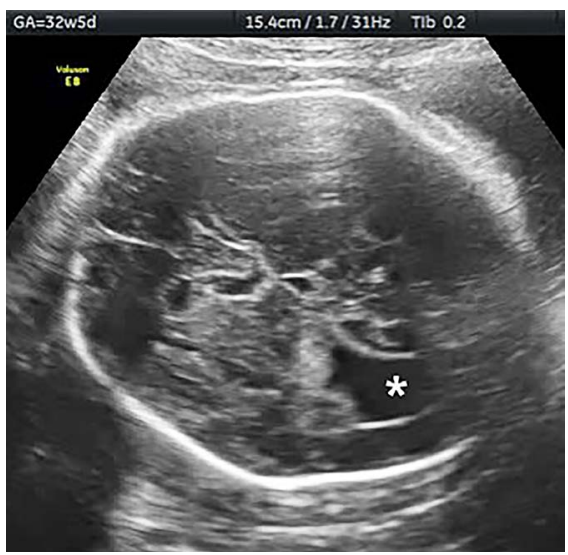

A

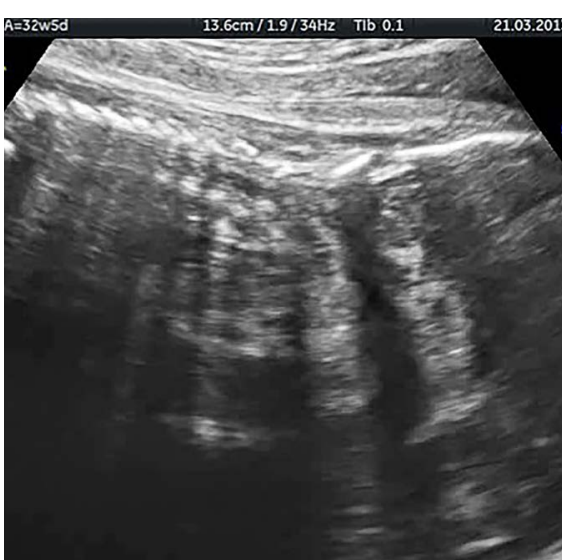

D

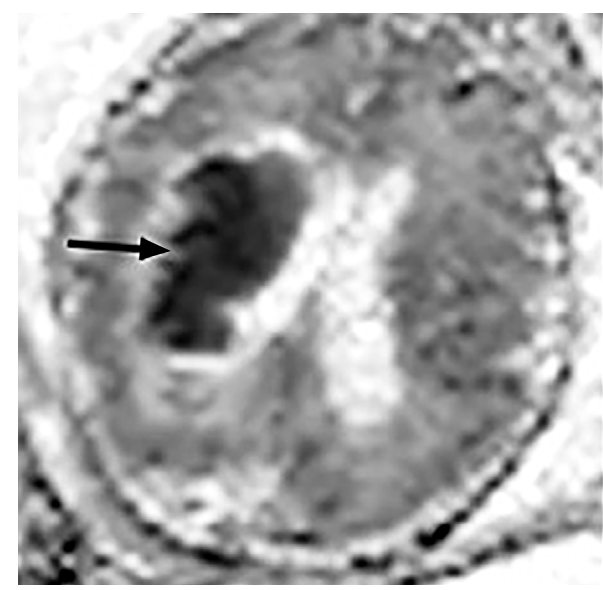

F

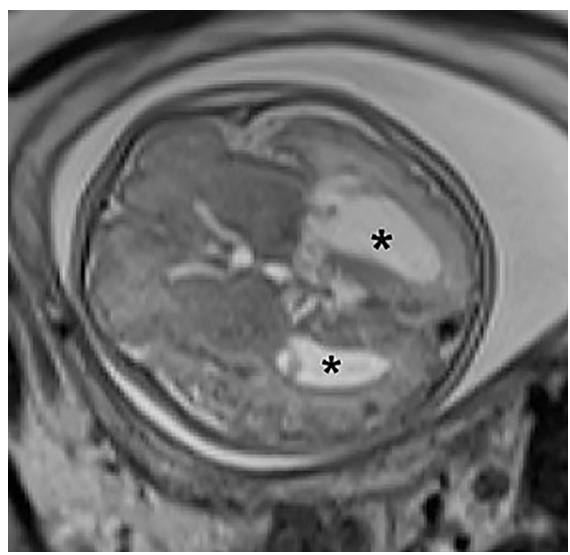

B

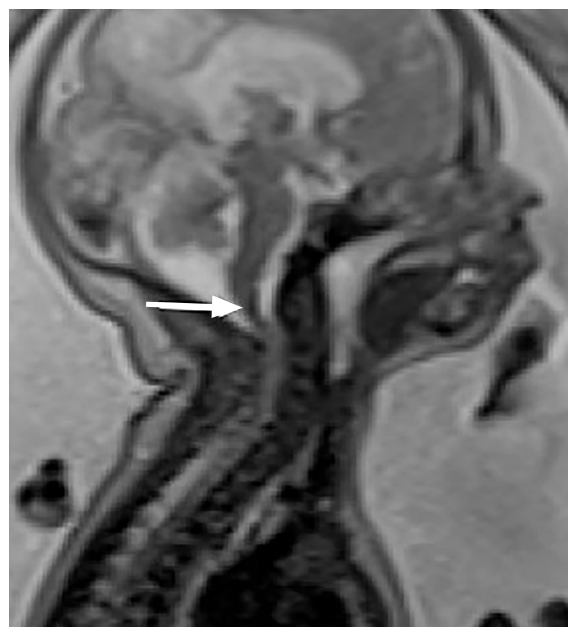

E

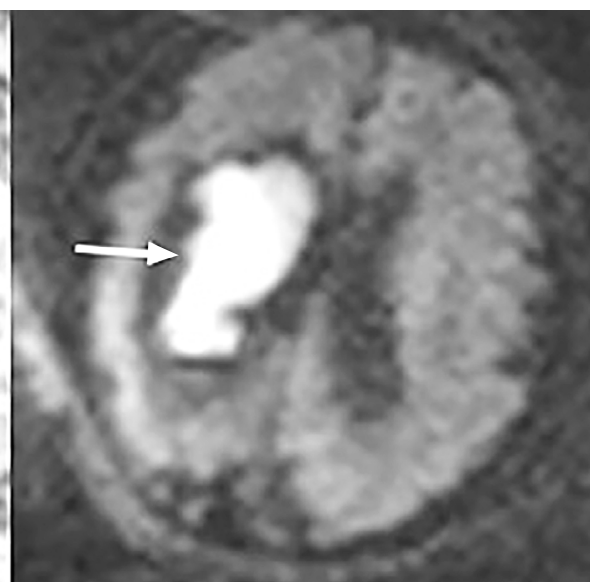

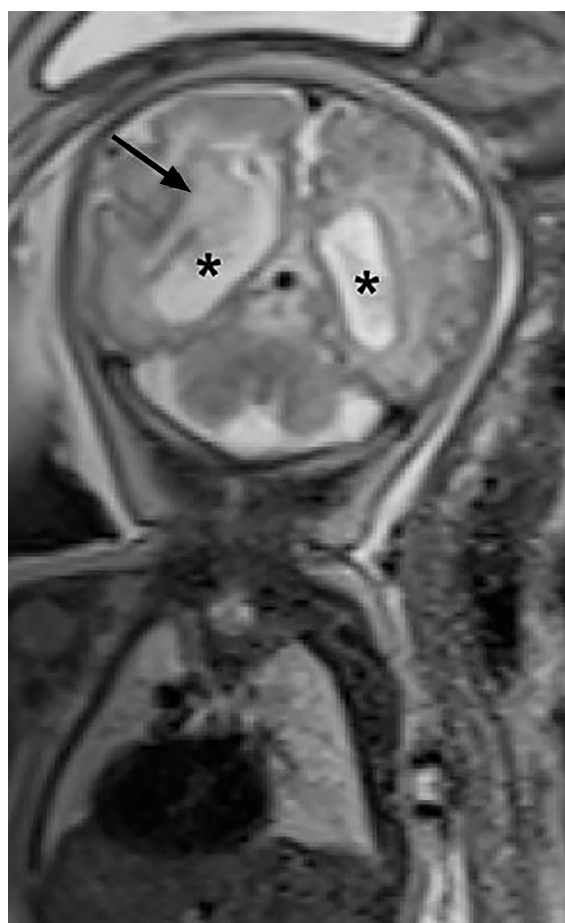

C

Fig. 2. Fetus with left ventricular dilatation at 35 weeks.

A-C. Axial ultrasonography (A), axial T2weighted (B) and coronal T2-weighted (C) magnetic resonance imaging show the left ventricular dilatation (asterisks). A heterogeneous signal is present in the left hemisphere, close to the left ventricle $(C$, arrow). D. Brainstem is difficult to evaluate on sagittal ultrasonography. E. Sagittal T2weighted image shows brainstem tapering (arrow). F. Axial diffusion-weighted image (left) and corresponding apparent diffusion coefficient map (right) show a hematoma close to the left ventricle (arrows). 


\section{Corpus Callosum Agenesis}

The corpus callosum is an important cerebral commissure connecting the cerebral hemispheres. It is formed from the anterior to the posterior commissure, with the exception of the rostrum [13]. Corpus callosum agenesis can be diagnosed with US, but MRI has become crucial for confirming the diagnosis in nondefinitive cases. With MRI, the corpus callosum can be directly visualized in the sagittal and coronal planes as a curvilinear $\mathrm{T} 2$ hypointense structure located at the superior margin of the lateral ventricles, superior to the fornices. The diagnosis may also be confirmed based

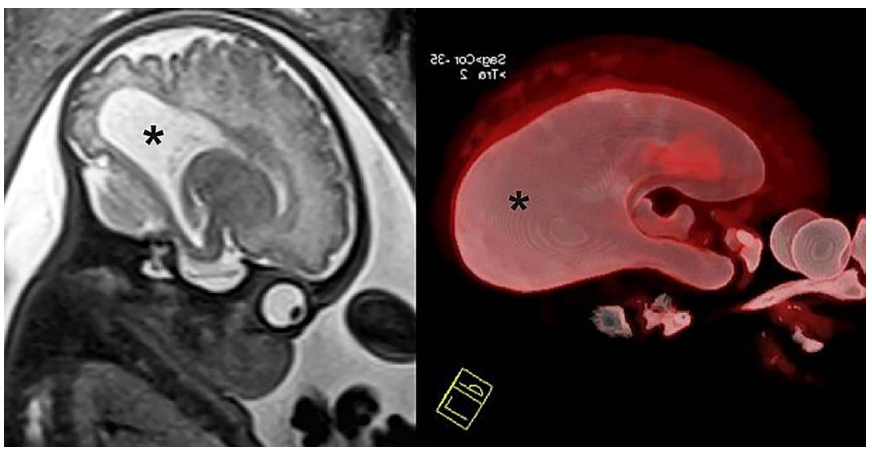

Fig. 3. Fetus with ventriculomegaly at 34 weeks. Sagittal T2weighted (left) and 3-dimensional reconstruction (right) images of magnetic resonance imaging demonstrate an enlarged posterior horn in the lateral ventricles (asterisks).

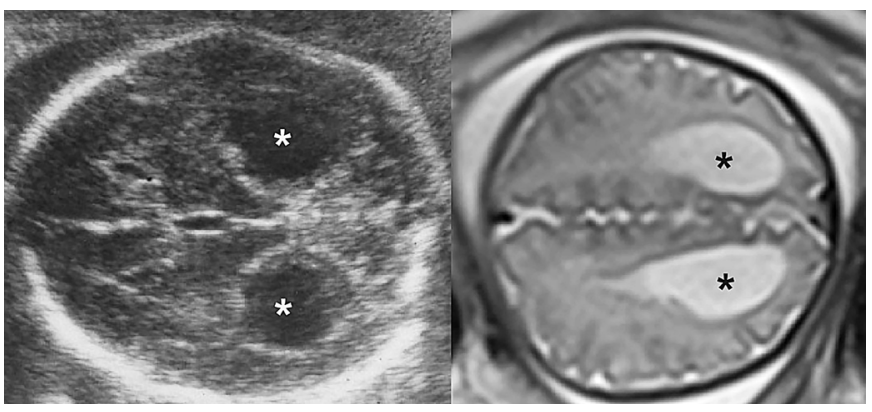

A

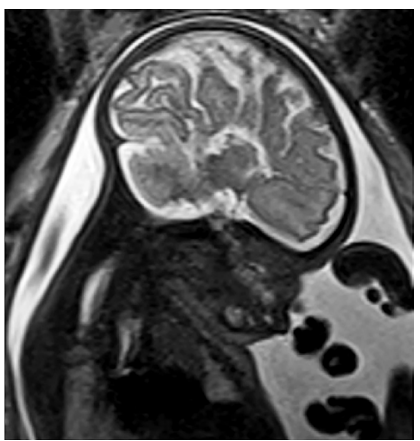

C

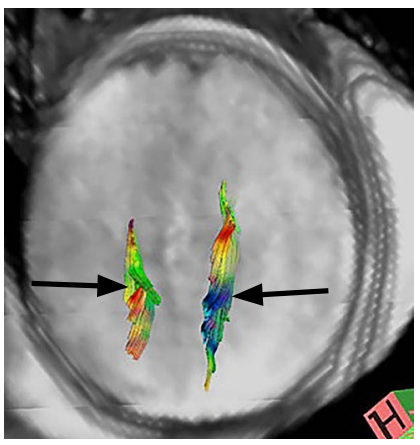

D on indirect signs such as parallelism of the lateral ventricles, the rise of the third ventricle, dilatation of the occipital horn of the lateral ventricles (colpocephaly), the absence of the cingulate gyri, and the presence of the bands of Probst, consisting of fibers that fail to reach the contralateral hemisphere and subsequently curve, causing an indentation on the anteromedial wall of the frontal horn (Fig. 4) [14]. Fetal MRI can also reveal other callosal anomalies, including partial agenesis, dysgenesis, and hypoplasia. Moreover, associated malformations involving the supratentorial and infratentorial structures are common (in up to $80 \%$ of cases) and associated extra-CNS anomalies may occur, including congenital heart disease, skeletal defects, and genitourinary defects (in up to $60 \%$ of cases) $[1,13,14]$.

\section{Holoprosencephaly}

Holoprosencephaly is a disorder of early origin, observed even during brain organogenesis, and results from a failure of forebrain cleavage [15]. Depending on the degree of severity, it is classified as alobar, semilobar, and lobar, with specific imaging findings for each form (Table 1). The incidence is approximately one in 10,000 births, and the prognosis of the alobar and semilobar forms is poor. Survival with milder (lobar) forms of the disorder is commonly associated with mental retardation [15]. The development of the face is related to the formation of the brain; hence, defects of the face may occur, ranging

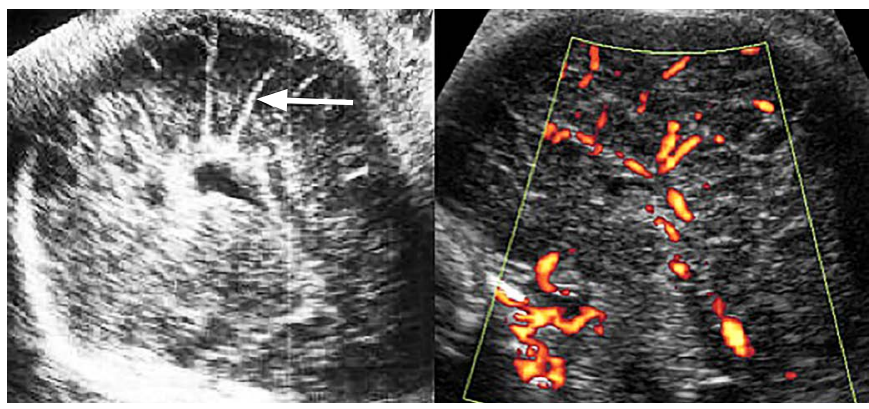

B

Fig. 4. Fetus with agenesis of the corpus callosum at 35 weeks. A. Axial ultrasonography (left) and magnetic resonance imaging (right) show an enlarged posterior horn of the lateral ventricle (asterisks). B. Coronal gray-scale (left) and power Doppler (right) ultrasonography shows an absence of the cingulate gyri and radial arrangement of the gyri (arrow). C. Sagittal T2-weighted magnetic resonance imaging also shows the same features on ultrasonography. D. Axial tractography shows the bands of Probst (arrows). 
from mild hypotelorism to cyclopia. US is a very effective method for diagnosing alobar and semilobar holoprosencephaly. Although only a few reports have been published in the literature, MRI appears to have real benefits for characterizing the lobar form and for confirming previous US findings for the alobar and semilobar forms (Fig. 5).

\section{Hydranencephaly}

Hydranencephaly consists of the complete or nearly complete

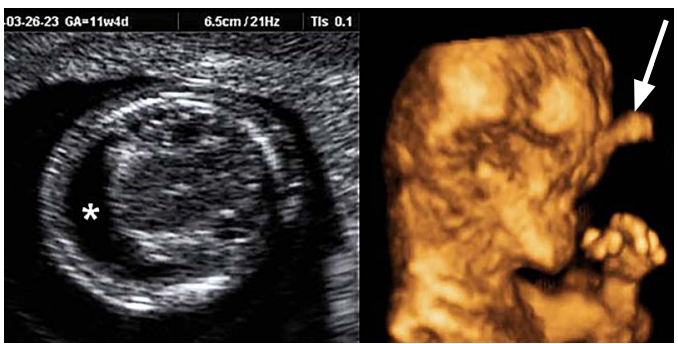

A

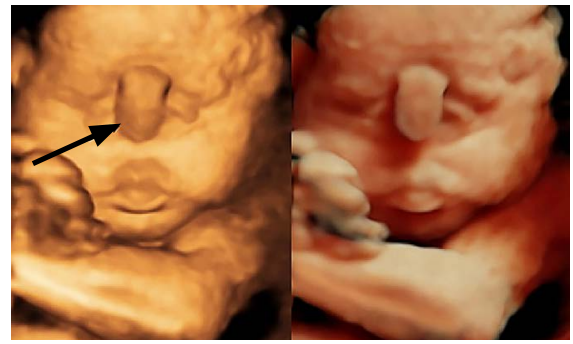

B

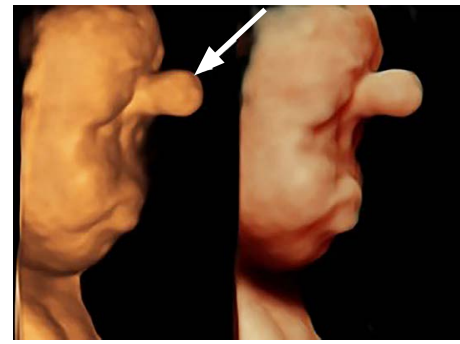

C

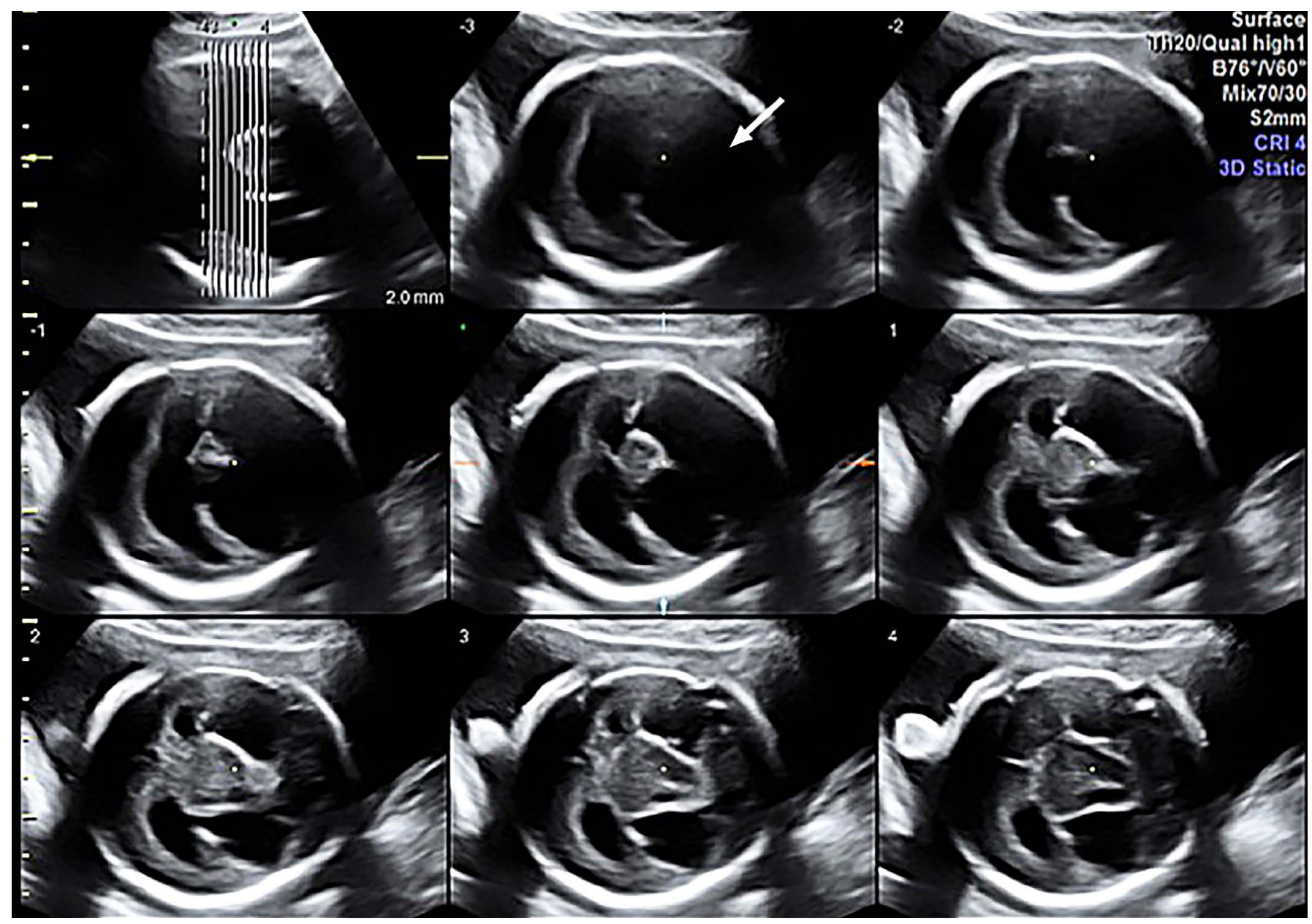

D

Fig. 5. Fetus at 11 weeks with alobar holoprosencephaly.

A. Axial ultrasonography (left) demonstrates fusion of the thalamus and ventricles (asterisk), which is also shown on a 3-dimensional rendering mode view (right) with a proboscis (arrow). B. Anterior views of 3-dimensional ultrasonography in the rendering (left) and HDLive modes (right) of the face show a proboscis (arrow). C. Profile views of 3-dimensional ultrasonography in the rendering (left) and HDLive modes (right) of the fetus show the proboscis (arrow). D. Serial images of 3-dimensional ultrasonography (tomographic ultrasound imaging mode) show the fusion of the ventricles (arrow). 


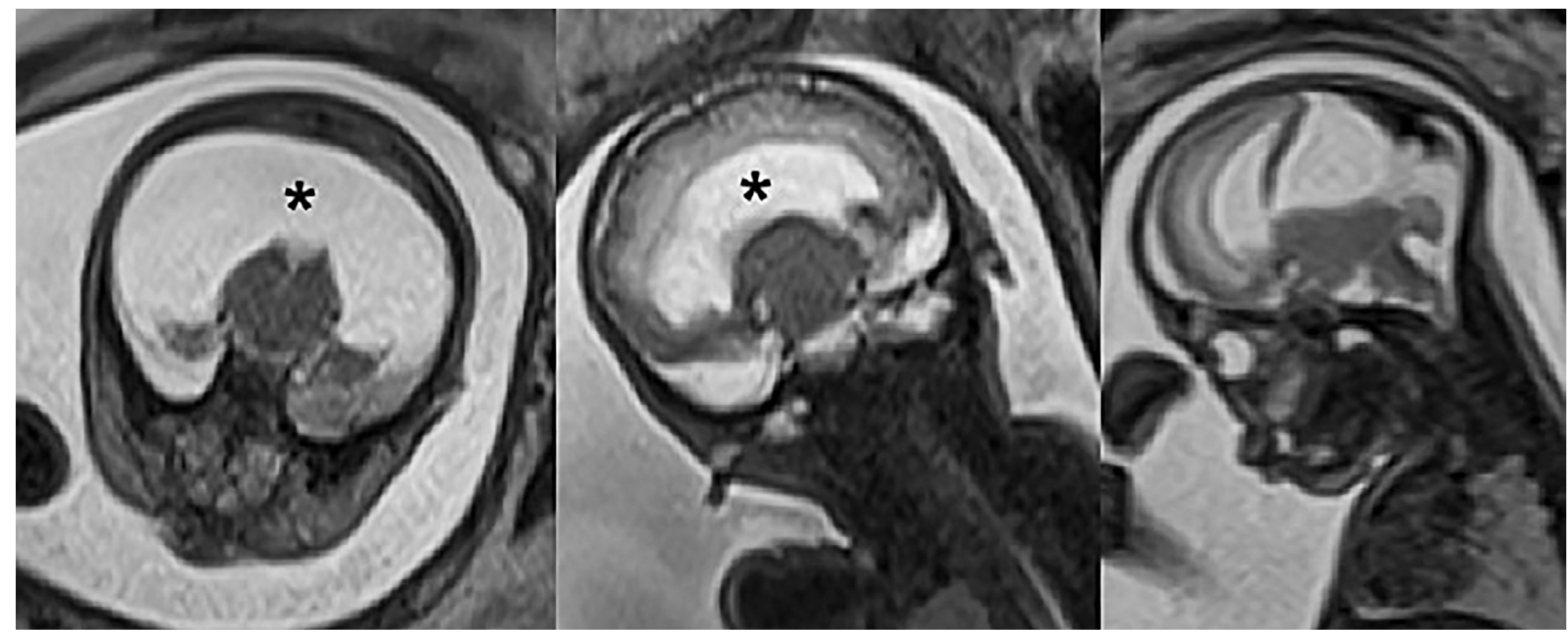

$\mathrm{E}$

Fig. 5. E. Axial (left), coronal (middle), and sagittal (right) T2-weighted magnetic resonance images show the monoventricle (asterisks) and fused cerebral hemispheres.

Table 1. Types of holoprosencephaly

\begin{tabular}{llll}
\multicolumn{1}{c}{ Finding } & \multicolumn{1}{c}{ Alobar } & \multicolumn{1}{c}{ Semilobar } & Lobar \\
\hline Craniofacial anomaly & Severe & Variable & Absent/minimal \\
Ventricles & Single holoventricle & Rudimentary occipital horns & Rectangular frontal horns \\
Septum pellucidum & Absent & Absent & Absent \\
Cerebral falx & Absent & Partial & Well formed \\
Interhemispheric fissure & Absent & Partial & Present/anterior-inferiorfusion \\
Thalami, basal ganglia & Fused & Partially separated & Separated \\
\hline
\end{tabular}

destruction of the cerebral cortex and basal ganglia. The etiology of this lesion is heterogeneous, and brain injury may be caused by vascular changes (complete and bilateral obstruction of internal carotid arteries) or congenital infections (cytomegalovirus and toxoplasmosis) $[16,17]$. The vertebral artery system is relatively intact in hydranencephaly, leading to significant preservation of posterior fossa structures and of the inferior and posterior portions of the temporal and occipital lobes $[16,17]$. On MRI, despite the absence of the cerebral hemispheres, the brainstem, thalamus, and cerebellum are present. The falx is also present, although sometimes reduced, with a large amount of fluid and necrotic debris above the unfused thalami and cerebellum (Fig. 6) $[16,17]$. When hydranencephaly is suspected, the differential diagnosis must include hydrocephalus and alobar and semilobar holoprosencephaly. In such cases, MRI findings may help differentiate these lesions, since MRI enables the specific evaluation of the anatomy and a comparison between the two hemispheres without interference from the ossified calvaria. In these cases, the presence of the falx is important for differentiating hydranencephaly from severe alobar holoprosencephaly, in which the falx is absent [17].

\section{Schizencephaly and Porencephaly}

Schizencephaly and porencephaly are pathologies of different origins that have a similar appearance when assessed using US. For this reason, MRI plays an important role in the differentiation of these entities, since it provides a high contrast between the tissues and better access to the entire parenchyma.

Schizencephaly is considered to be an abnormality of neuronal migration characterized by clefts that extend from the subarachnoid space to the subependyma of the ventricles [16]. The suspected diagnosis is usually due to an asymmetric dilatation of the lateral ventricles, while the third ventricle remains normal. On MRI, a more detailed evaluation may demonstrate a lesion surrounded by gray matter converging to the lateral ventricles and deforming their 


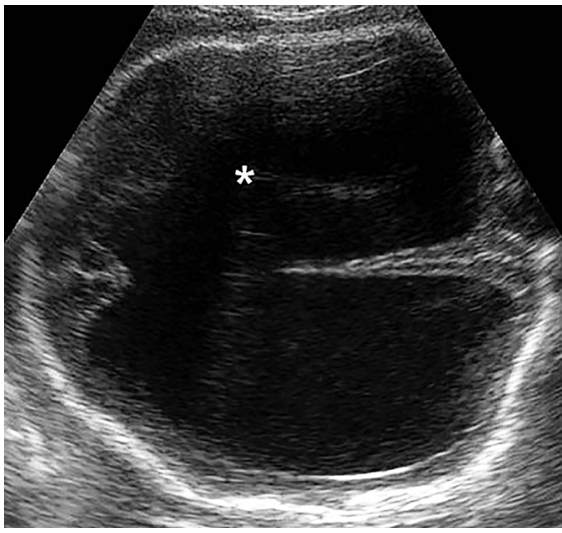

A

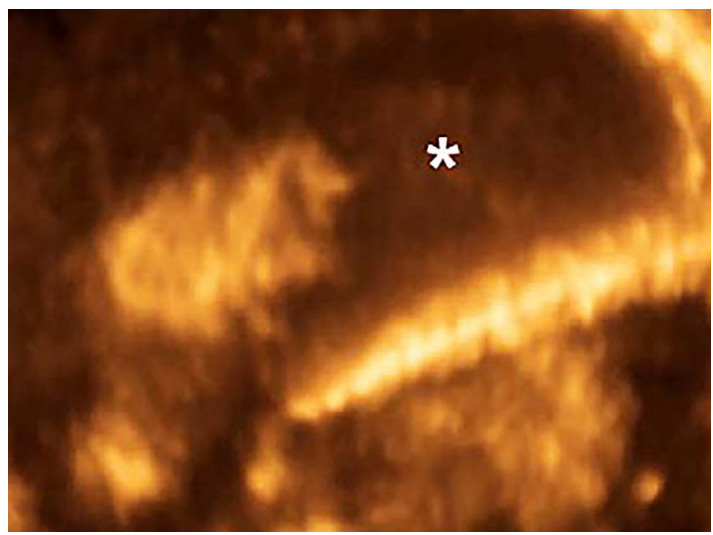

B

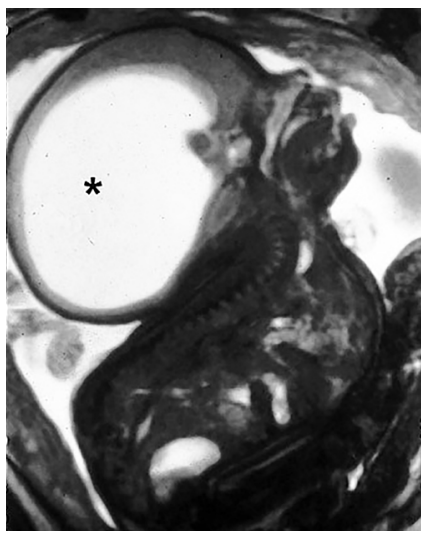

C

Fig. 6. Fetus with hydranencephaly at 22 weeks.

$A, B$. Axial ultrasonography (A) and 3-dimensional ultrasonography in the rendering mode (B) demonstrate the hydranencephaly (asterisks). C. Sagittal T2-weighted magnetic resonance imaging shows the brain parenchyma forming a thin band with hydranencephaly (asterisks).

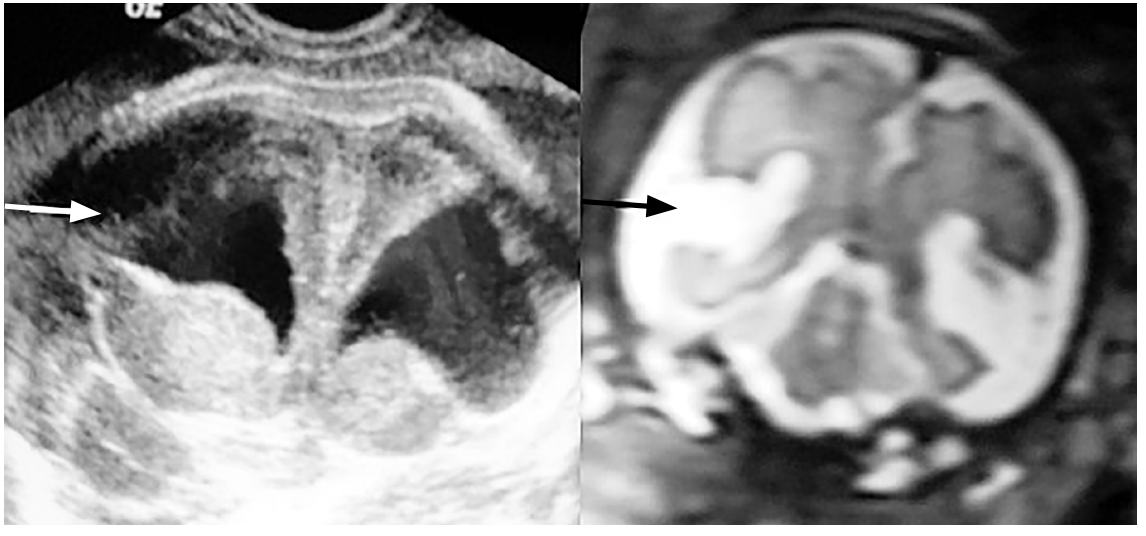

A

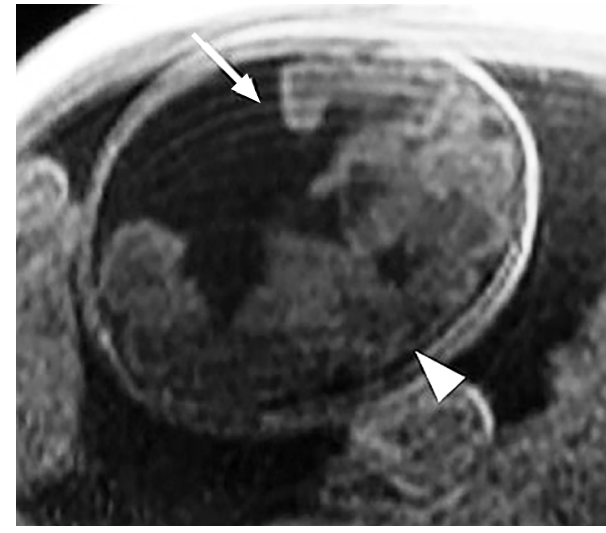

B

Fig. 7. Fetus with schizencephaly at 32 weeks.

A. Coronal ultrasonography (left) and T2-weighted magnetic resonance imaging (right) show a crack in the brain parenchyma extending from the surface to the subarachnoid space (arrows). B. Axial T1-weighted magnetic resonance imaging also shows a crack (arrow) surrounded by the gray matter (arrowhead).

contour (Fig. 7), differentiating this entity from porencephaly [16].

In contrast, porencephaly results from the localized destruction of brain tissue during pregnancy, usually due to ischemic necrosis or to hemorrhage [17]. This destructive process results in the liquefaction and reabsorption of the destroyed parenchyma, leading to the formation of a walled cavity filled with fluid, which may sometimes present a direct communication to the ventricle [17]. This condition can involve the entire thickness of the cerebral cortex, forming large cavities (Fig. 8), or may be restricted to a single layer.

\section{Microcephaly}

Microcephaly is defined as a significant reduction in head circumference below the fifth percentile or two standard deviations below average.

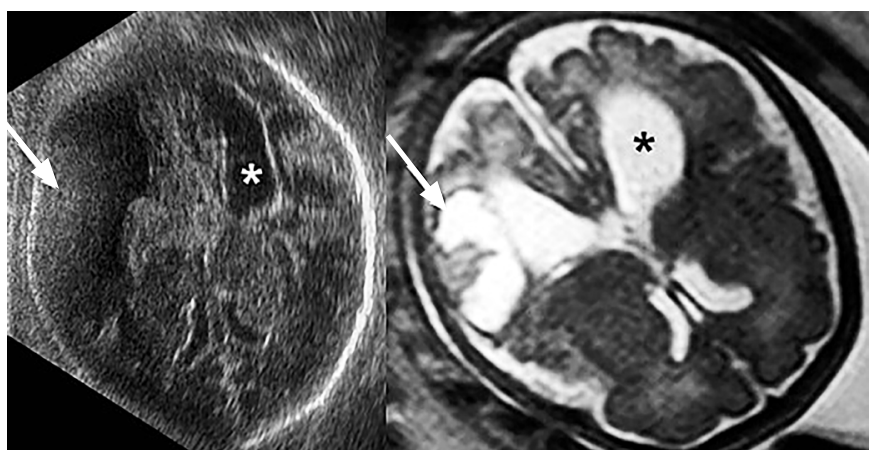

Fig. 8. Fetus with porencephalic cysts at 30 weeks. Axial ultrasonography (left) and T2-weighted magnetic resonance imaging (right) demonstrate a parenchymal cavitation (arrows) in the temporoparietal lobe. The ventricular dilatation should be noted (asterisks). 
It is usually detected after 24 weeks, since it is easier to diagnose further along in gestation due to the contrast between the size of the head and the fetal body. The main causes are autosomal recessive or dominant disorders, infections (cytomegalovirus, toxoplasmosis, rubella, and Zika virus), radiation, drugs, alcohol, and hypoxia. Gyration anomalies, such as polymicrogyria, lissencephaly, or simplified gyral patterns, may be associated with microcephaly [18]. In such cases, US analysis of the brain is often limited due to the poor acoustic windows resulting from the ossified calvaria and the poor definition of the brain parenchyma, especially when the extra-axial fluid space is also small. MRI may be helpful in this situation, enabling more detailed examination of brain development and the parenchyma (Fig. 9).

\section{Chiari Malformation}

Chiari malformations are congenital abnormalities of the hindbrain, usually associated with hydrocephalus $[16,19]$. Types I and II are the most frequent. Chiari I involves the displacement of the cerebellar tonsils into the upper cervical canal, whereas Chiari II is a herniation of the lower cerebellar vermis and the fourth ventricle [16]. Chiari II is found in $65 \%-100 \%$ of severe spina bifida cases. For this reason, when Chiari II malformation is suspected, the possible presence of associated meningomyelocele must be assessed. The US findings of Chiari II include a small posterior fossa, hypoplastic cerebellar hemispheres, and ventricular dilatation, and these findings usually allow this condition to be diagnosed [19]. However, a more detailed analysis of the associated cord malformations and brain parenchyma abnormalities is sometimes difficult with US due to shadowing of the vertebral bodies and calvaria [19]. In such cases, fetal MRI may help conduct a complete analysis of CNS development. On MRI, Chiari II may present a small posterior fossa with displacement of the inferior vermis, along with a small fourth ventricle that is elongated and displaced inferiorly (Fig. 10). Dysgenesis of the corpus callosum, polymicrogyria, and hydrocephalus are present in approximately $90 \%$ of cases, and spina bifida is found in almost $100 \%$ of cases [16].

There is another severe form of Chiari malformation, known as type III. This form is rare, and consists of encephalocele with herniation of the posterior fossa contents (Fig. 11) and sometimes the occipital lobe. The herniated tissue is always abnormal, showing areas of necrosis, gliosis, and fibrosis.

\section{Iniencephaly}

Iniencephaly is a rare malformation of the neural tube occurring early in the embryonic development of the fetus (around the third week). It is characterized by marked retroflexion of the head due to a defect in the occipital region involving the foramen magnum and vertebral axis [20]. The vertebral changes are described in terms of an inability to visualize the posterior arches with fusion of the anterior aspect of the vertebral body [8]. The face is turned upward, with skin covering the mandibular and chest areas [20]. Associated anomalies are present in $84 \%$ of affected fetuses, including hydrocephalus, Dandy-Walker malformation, encephalocele, meningocele, diaphragmatic hernia, omphalocele, and cardiac and

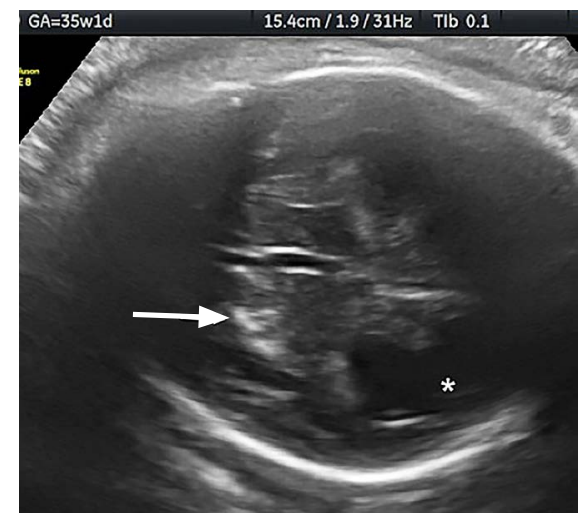

A

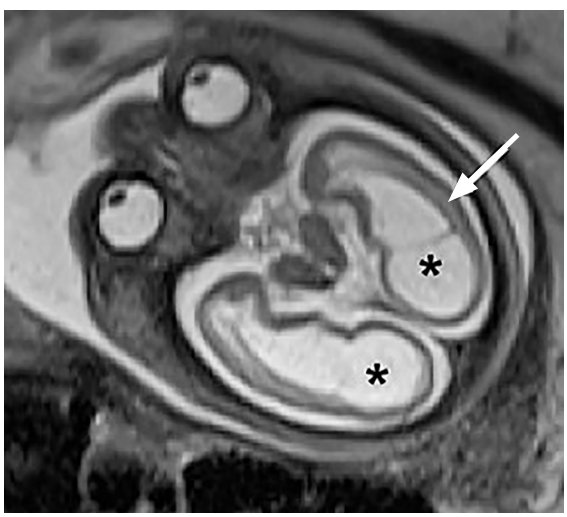

B

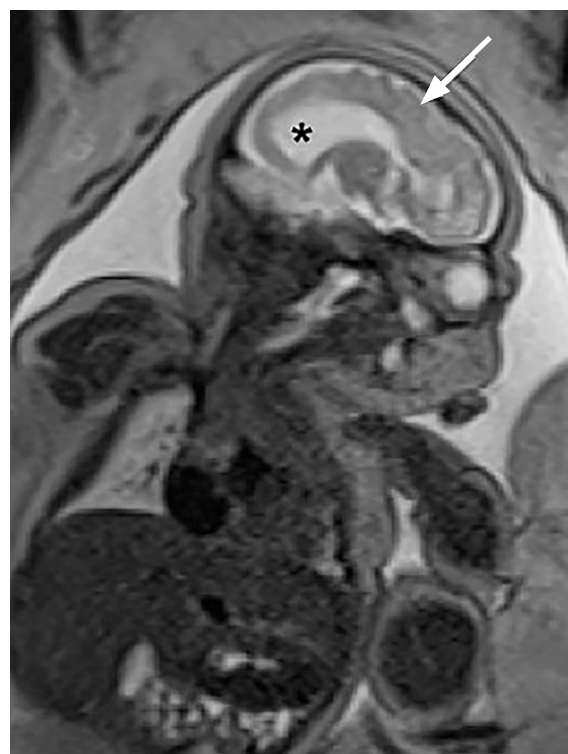

C weighted magnetic resonance imaging shows the ventricular dilatation (asterisk) and relative smoothness of the brain surface, brain atrophy, and irregular cortex (pachygyria) (arrow). 
aortic arch anomalies. US findings may suggest the diagnosis, but it is usually difficult to visualize the entire spine in the longitudinal plane using this modality, and the details of the fetal brain and spinal cord may not be satisfactorily observed. MRI can delineate intracranial and intraspinal anomalies in greater detail (Fig. 12).

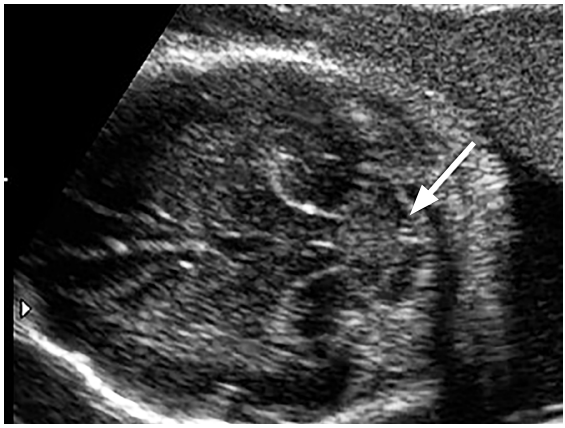

A

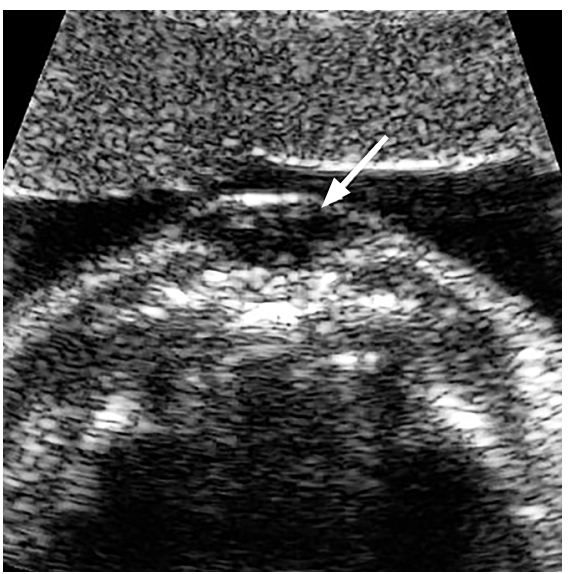

D

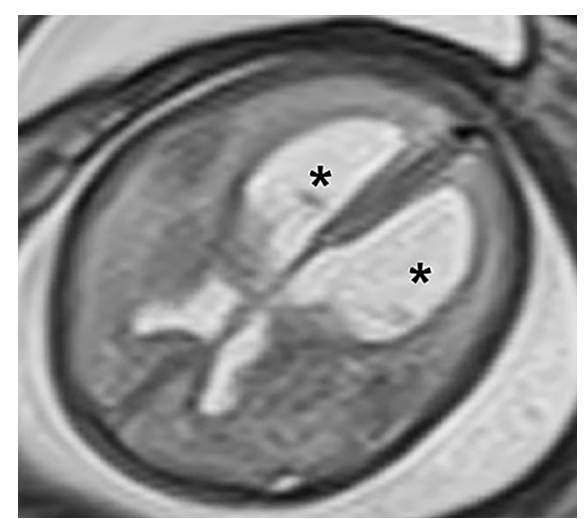

G

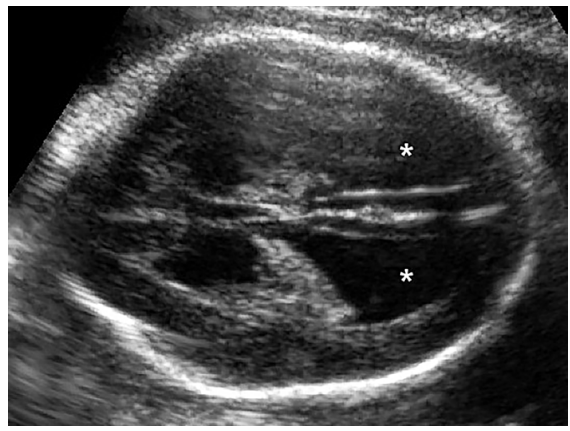

B

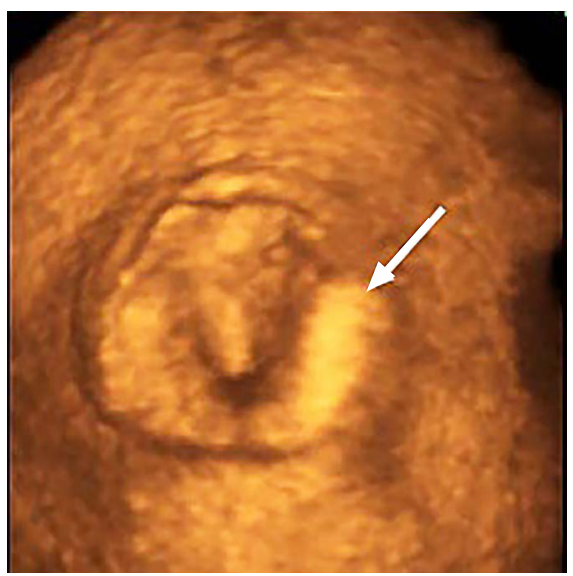

E

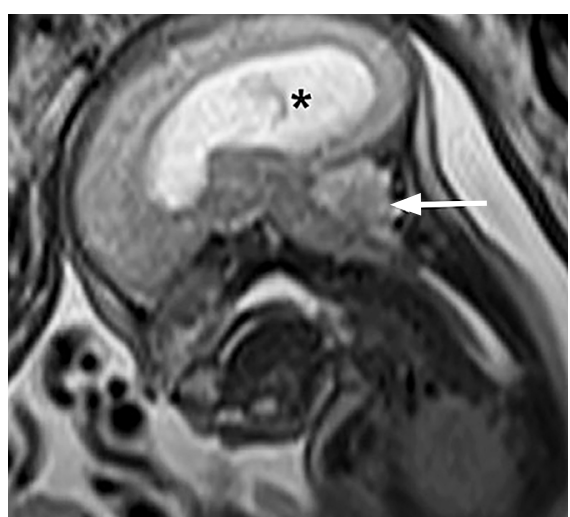

$\mathrm{H}$

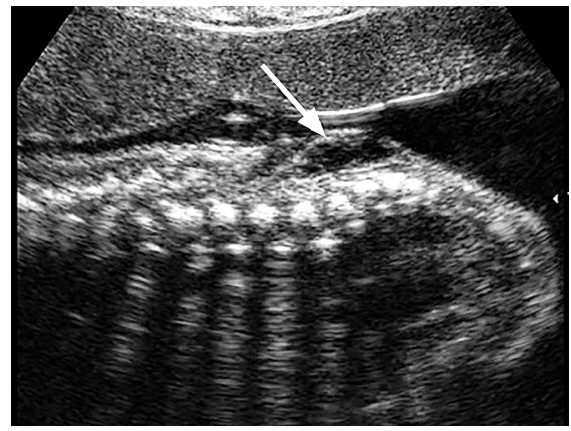

C

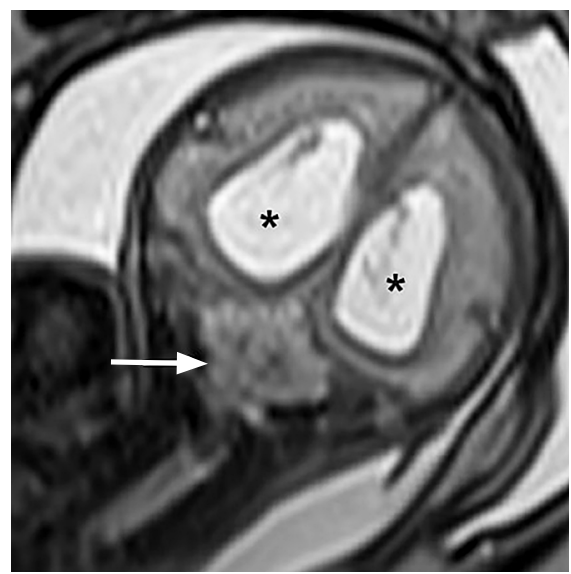

F

Fig. 10. Fetus with a Chiari II malformation at 26 weeks.

A. Axial ultrasonography shows the banana sign of cerebellar herniation (arrow). B. Axial ultrasonography shows the lemon sign of bilateral depression of the frontal skull and ventricular dilatation (asterisks). C, D. Sagittal (C), and axial (D) sonographic images demonstrate a meningocele (arrows). E. Meningocele (arrow) should be noted in the 3-dimensional ultrasonography in the rendering mode. F. Coronal T2weighted magnetic resonance imaging shows a small posterior fossa, ventriculomegaly (asterisks), and obliteration of the cisterna magna (arrow). G. Axial T2-weighted magnetic resonance imaging shows the ventricular dilatation (asterisks). H. Sagittal T2-weighted magnetic resonance imaging shows the ventricular dilatation (asterisk) and cerebellar herniation (arrow). 


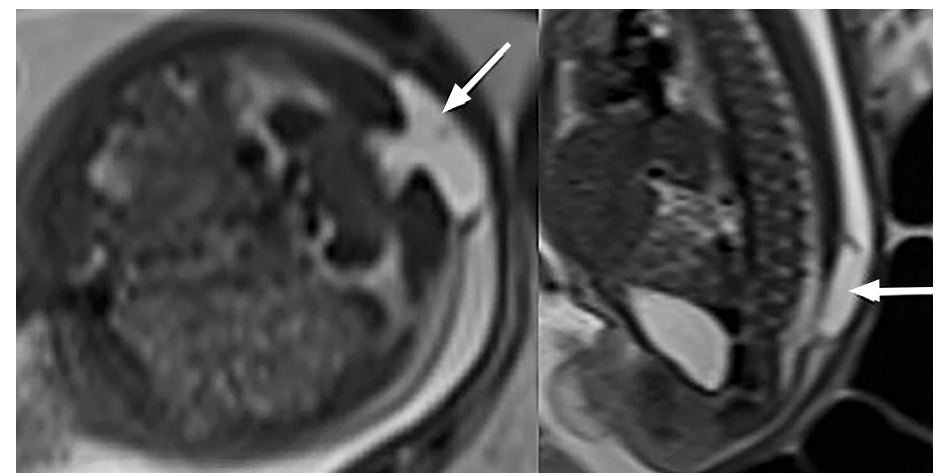
I

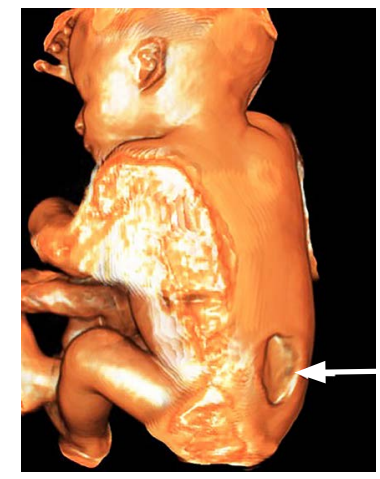

J
Fig. 10. I. Axial (left) and sagittal (right) images of T2weighted magnetic resonance imaging show a meningocele (arrows). J. Three-dimensional reconstruction from magnetic resonance imaging shows a meningocele (arrow).

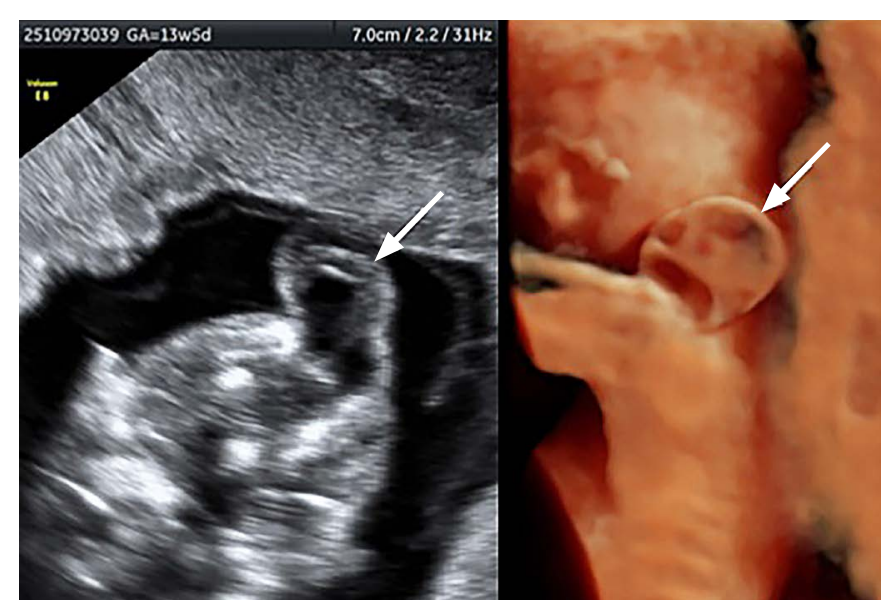

A

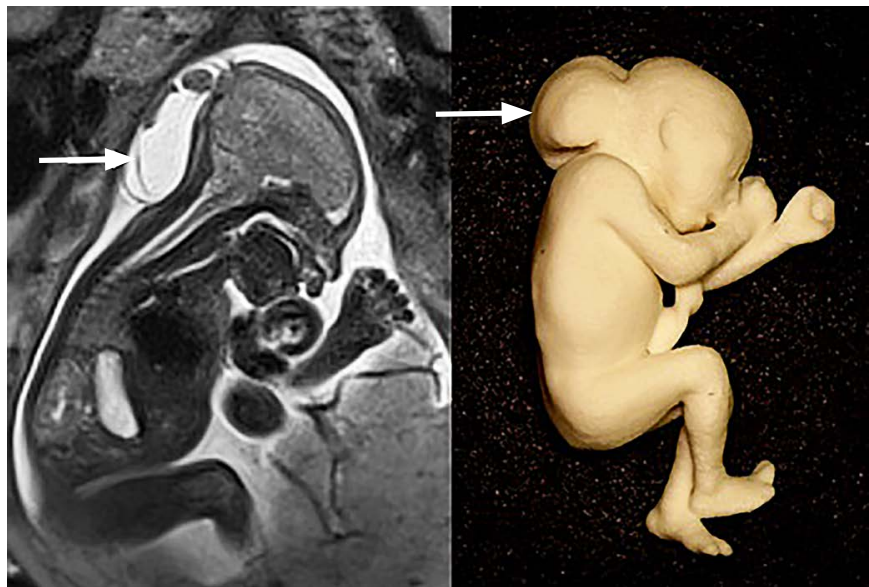

B

Fig. 11. Fetus with a Chiari III malformation at 13 weeks and 5 days.

A. Axial ultrasonography (left) and 3-dimensional ultrasonography in the HDLive mode (right) show a high cervical encephalocele with posterior fossa content (arrows). B. Sagittal T2-weighted magnetic resonance imaging (left) and 3-dimensional reconstruction image (right) show a large encephalocele (arrows).

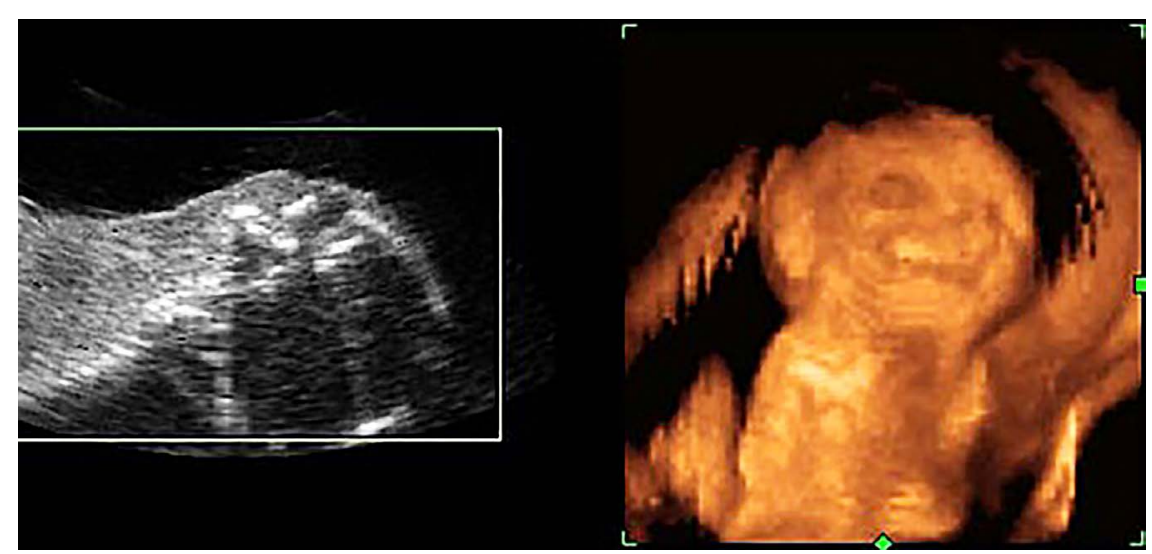

A

Fig. 12. Fetus with iniencephaly at 28 weeks.

A, B. Sagittal ultrasonography (left) and 3-dimensional ultrasonography in the rendering mode (right) (A) and sagittal T2-weighted magnetic resonance imaging (B) demonstrate a short cervical spine with marked retroflexion. Hydrocephaly (asterisk) and dysraphism (arrow) should be noted.

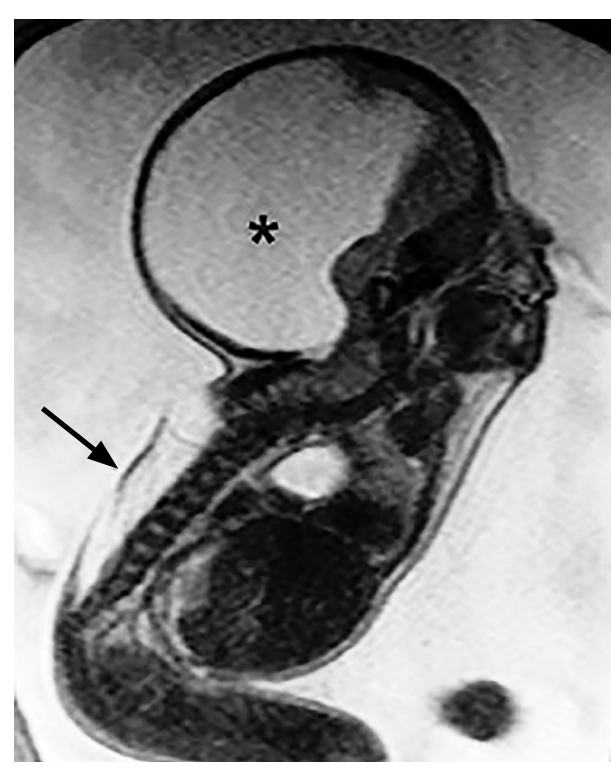

B 


\section{Dandy-Walker Malformation}

Dandy-Walker malformation is a developmental anomaly of the posterior fossa with an incidence of one in 25,000-35,000 live births and a slight female predominance. It is characterized by complete or partial agenesis of the vermis, cystic dilatation of the fourth ventricle, and enlargement of the posterior fossa, with superior displacement of the tentorium and the torcula herophili (confluence of venous sinuses) [21]. Due to the late embryological development of the cerebellum, a diagnosis of vermis agenesis or partial agenesis cannot be suggested until the end of the 19th

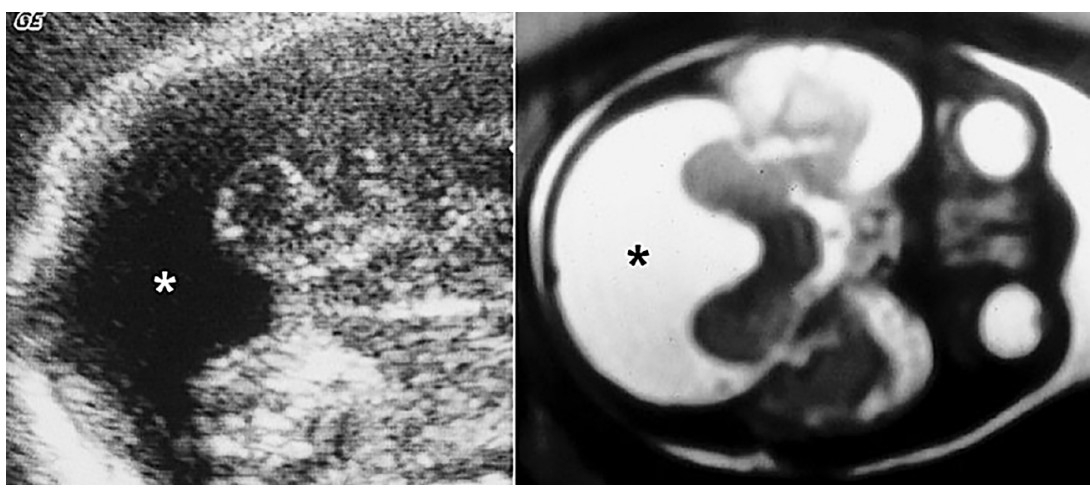

A

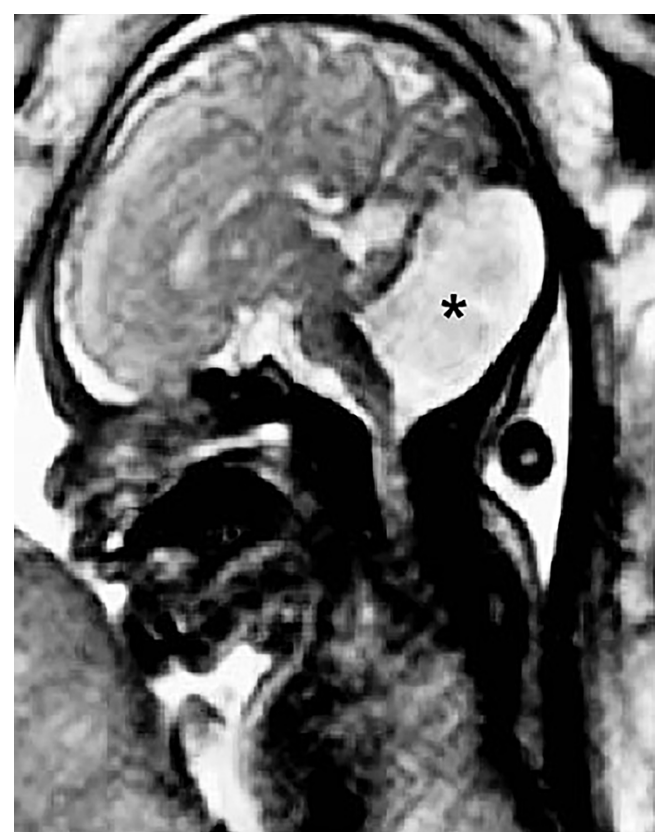

B

Fig. 13. Fetus with Dandy-Walker malformation at 28 weeks.

A. Axial ultrasonography (left) and T2-weighted magnetic resonance imaging (right) demonstrate the enlargement of posterior fossa (asterisks). B. Sagittal T2-weighted magnetic resonance imaging shows a posterior fossa cyst (asterisk).

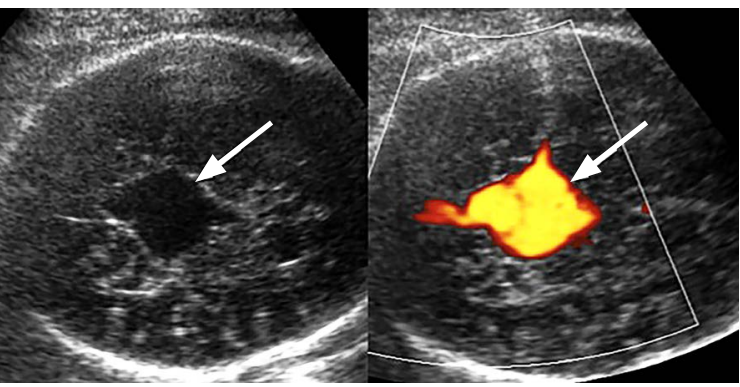

A

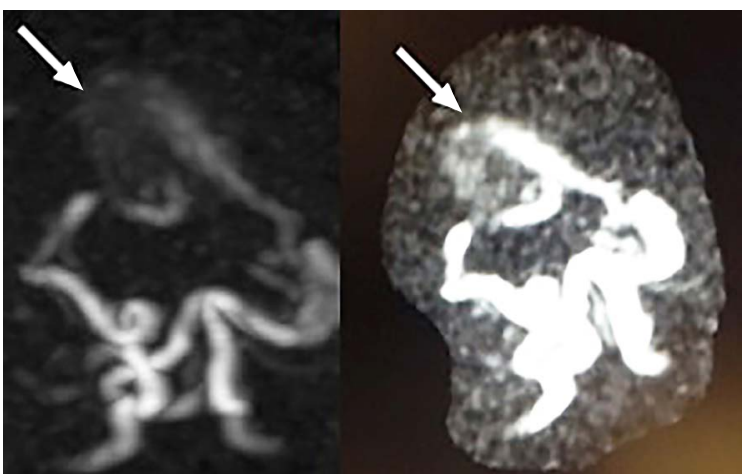

C

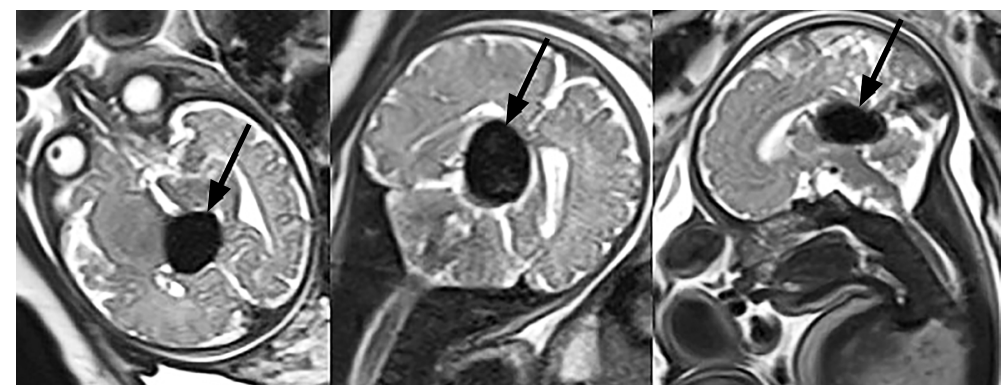

B

Fig. 14. Fetus with an aneurysmal vein of Galen malformation at 28 weeks. A. Axial ultrasonography (left) and corresponding power Doppler image (right) demonstrate a large vascular lesion in the midline (arrows). B. Axial (left), coronal (middle), and sagittal (right) images of T2-weighted magnetic resonance imaging taken at the same time show a round midline lesion with a markedly low signal, representing an aneurysmal vein of Galen malformation (arrows). C. Three-dimensional vascular lesion (arrows) is reconstructed on fetal magnetic resonance imaging (left) and postnatal computed tomography (right). 
week, when the cerebellar vermis should be fully developed [22]. Associated malformations are frequent, including corpus callosum agenesis $(25 \%)$, corpus callosum lipoma, malformation of the cerebral gyri, holoprosencephaly (25\%), cerebellar heterotopia $(25 \%)$, dysplasia of the cingulated gyrus $(25 \%)$, and gray matter heterotopia $(5 \%-10 \%)$. Moreover, there is a high incidence of karyotypic abnormalities, mainly trisomy 18 and 13, as well as triploidy (up to $40 \%$ of cases) [22]. MRI may add important information when the US analysis of the vermis malformation is insufficient, enabling more accurate evaluation of the posterior fossa structures and facilitating a more specific diagnosis (Fig. 13).

\section{Vein of Galen Malformations}

Malformations of the vein of Galen are characterized by dilatation of the venous structures of the galenic system with anomalous arteriovenous communications [23]. Both Doppler US and fetal MRI accurately visualize the dilated vein of Galen in the midline region. On MRI, the lesion usually shows a heterogeneous signal, predominantly hypointense on all sequences due to the turbulent flow (Fig. 14). Fetal MRI is also a more precise imaging method to visualize the entire brain parenchyma, which may present hemorrhage secondary to thrombosis, as well as dilation of arterial and venous structures adjacent to the lesion and hydrocephalus [23].

\section{Tuberous Sclerosis}

Tuberous sclerosis is characterized by the development of hamartomatous lesions in many tissues, particularly the brain, skin, heart, and kidneys. It shows an autosomal dominant inheritance pattern, although the majority of cases represent new mutations in families not previously affected [8]. Fetal cardiac tumors (rhabdomyomas) are the main abnormality observed on prenatal US [24]. These tumors are characterized as echogenic masses in the heart and are located in the ventricular walls, often protruding into the heart cavity. Approximately $50 \%$ of fetuses with rhabdomyoma have tuberous sclerosis. The main brain lesions of tuberous sclerosis are subependymal nodules and cortical tubers. Both lesions

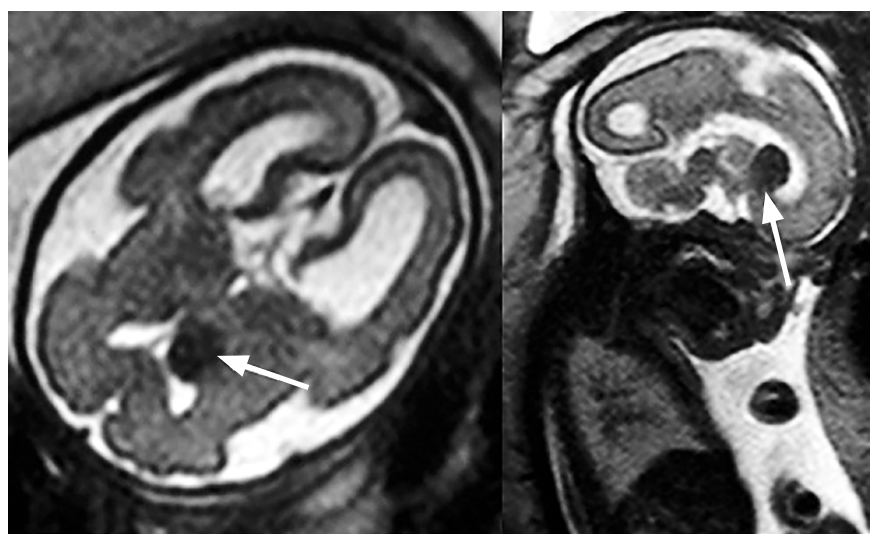

Fig. 15. Fetal with tuberous sclerosis at 26 weeks. Axial (left) and sagittal (right) images of T2-weighted magnetic resonance imaging show a subependymal nodule (arrows).

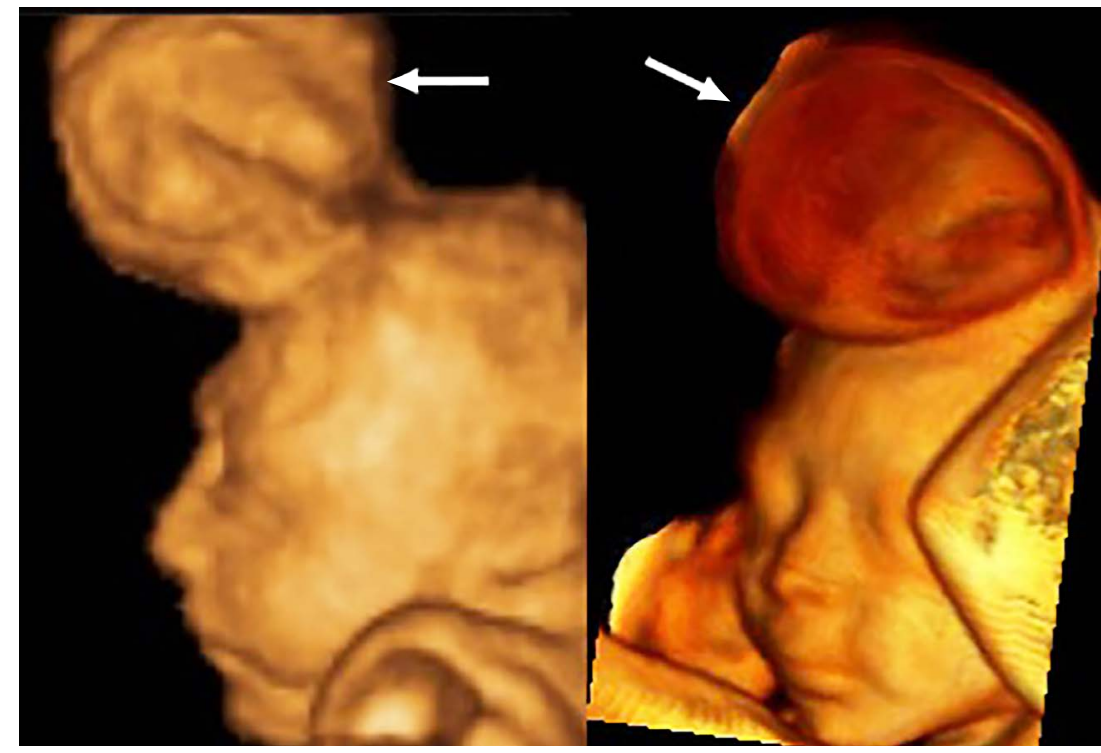

A

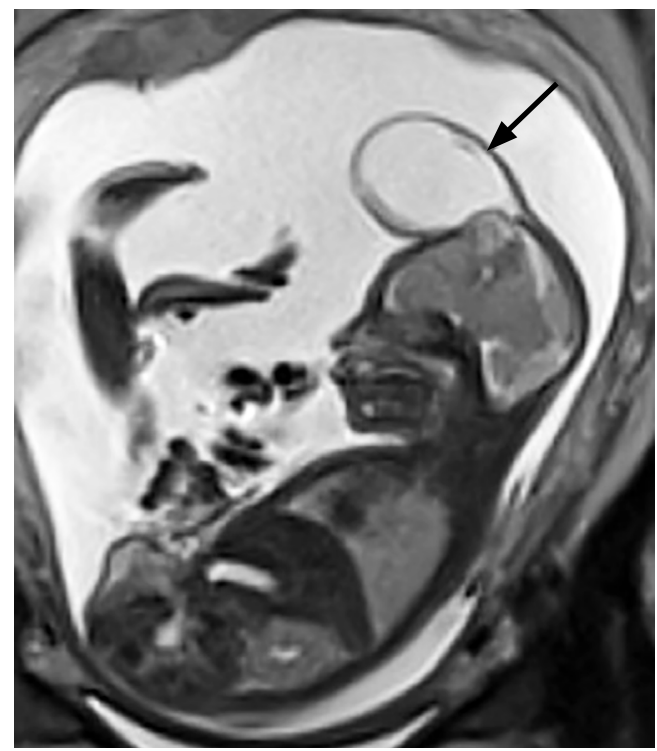

B

Fig. 16. Fetus with encephalocele at 26 weeks.

A. Three-dimensional reconstruction of the fetal profile by ultrasonography (left) and magnetic resonance imaging (right) demonstrate an encephalocele (arrows). B. Sagittal T2-weighted magnetic resonance imaging demonstrates an encephalocele (arrow). 
are visualized well on T2-weighted images of the fetal brain. Subependymal nodules are situated at the edges of the lateral ventricles and usually have a low signal on T2-weighted images (Fig. 15). Cortical tubers may be identified as hypointense areas in the cerebral cortex on T2-weighted images [24].

\section{Encephalocele}

Encephalocele is a neural tube defect resulting in a midline mass overlying a skull defect. This condition is frequently associated with other brain malformations, such as hydrocephalus, facial clefts, cardiac abnormalities, and genital malformations [25]. The occipital location is the most frequent (75\% of cases), followed by the frontal (15\% of cases) and parietal (10\%) areas. The lesion may be purely cystic (Fig. 16) or may present brain tissue incorporated within the mass. When the lesion is purely cystic, the identification of the skull defect is a target for diagnosis. In such cases, fetal MRI may help to identify the defect.

\section{Conclusion}

The diagnosis of a fetal brain anomaly is a critical stressor for pregnant parents, and effective counseling depends on an accurate prenatal diagnosis. Moreover, the accurate diagnosis of antenatal conditions is essential, not only for the management of the affected pregnancy, but also for future pregnancies to aid in the identification of inheritable diseases and to provide information for accurate prenatal counseling. MRI of the fetal brain is an accurate imaging method that allows better characterization of lesions and of the remaining brain parenchyma, especially when US has limitations.

ORCID: Edward Araujo Júnior: http://orcid.org/0000-0002-6145-2532

\section{Conflict of Interest}

No potential conflict of interest relevant to this article was reported.

\section{References}

1. Glenn OA, Barkovich J. Magnetic resonance imaging of the fetal brain and spine: an increasingly important tool in prenatal diagnosis: part 2. AJNR Am J Neuroradiol 2006;27:1807-1814.

2. Girard N, Chaumoitre K, Chapon F, Pineau S, Barberet M, Brunel H. Fetal magnetic resonance imaging of acquired and developmental brain anomalies. Semin Perinatol 2009;33:234-250.

3. Victoria T, Jaramillo D, Roberts TP, Zarnow D, Johnson AM, Delgado $J$, et al. Fetal magnetic resonance imaging: jumping from 1.5 to 3 tesla (preliminary experience). Pediatr Radiol 2014;44:376-386.
4. Malinger G, Ben-Sira L, Lev D, Ben-Aroya Z, Kidron D, Lerman-Sagie T. Fetal brain imaging: a comparison between magnetic resonance imaging and dedicated neurosonography. Ultrasound Obstet Gynecol 2004;23:333-340.

5. Garel C. New advances in fetal MR neuroimaging. Pediatr Radiol 2006;36:621-625.

6. Al-Mukhtar A, Kasprian G, Schmook MT, Brugger PC, Prayer D. Diagnostic pitfalls in fetal brain MRI. Semin Perinatol 2009;33:251258.

7. Cook RJ, Erdman JN, Hevia M, Dickens BM. Prenatal management of anencephaly. Int J Gynaecol Obstet 2008;102:304-308.

8. Strunz K, Schmitz B, Boll D, Bode H, Terinde R. Clinical impact of fetal MRI in addition to ultrasonography in brain anomalies: three case reports. Ultraschall Med 2007;28:416-420.

9. Saleem SN, Said AH, Abdel-Raouf M, El-Kattan EA, Zaki MS, Madkour $\mathrm{N}$, et al. Fetal MRI in the evaluation of fetuses referred for sonographically suspected neural tube defects (NTDs): impact on diagnosis and management decision. Neuroradiology 2009;51:761772.

10. Gaglioti P, Oberto M, Todros T. The significance of fetal ventriculomegaly: etiology, short- and long-term outcomes. Prenat Diagn 2009;29:381-388.

11. Cardoza JD, Goldstein RB, Filly RA. Exclusion of fetal ventriculomegaly with a single measurement: the width of the lateral ventricular atrium. Radiology 1988;169:711-714.

12. Griffiths PD, Reeves MJ, Morris JE, Mason G, Russell SA, Paley MN, et al. A prospective study of fetuses with isolated ventriculomegaly investigated by antenatal sonography and in utero MR imaging. AJNR Am J Neuroradiol 2010;31:106-111.

13. Tang PH, Bartha Al, Norton ME, Barkovich AJ, Sherr EH, Glenn OA. Agenesis of the corpus callosum: an MR imaging analysis of associated abnormalities in the fetus. AJNR Am J Neuroradiol 2009;30:257-263.

14. Volpe P, Campobasso G, De Robertis V, Rembouskos G. Disorders of prosencephalic development. Prenat Diagn 2009;29:340-354.

15. Pulitzer SB, Simon EM, Crombleholme TM, Golden JA. Prenatal MR findings of the middle interhemispheric variant of holoprosencephaly. AJNR Am J Neuroradiol 2004;25:1034-1036.

16. Poe LB, Coleman LL, Mahmud F. Congenital central nervous system anomalies. Radiographics 1989;9:801-826.

17. de Laveaucoupet J, Audibert F, Guis F, Rambaud C, Suarez B, Boithias-Guerot $C$, et al. Fetal magnetic resonance imaging (MRI) of ischemic brain injury. Prenat Diagn 2001;21:729-736.

18. Garel C, Chantrel E, Elmaleh M, Brisse H, Sebag G. Fetal MRI: normal gestational landmarks for cerebral biometry, gyration and myelination. Childs Nerv Syst 2003;19:422-425.

19. Hosny IA, Elghawabi HS. Ultrafast MRI of the fetus: an increasingly important tool in prenatal diagnosis of congenital anomalies. Magn Reson Imaging 2010;28:1431-1439. 
20. McGahan JP, Pilu G, Nyberg DA. Neural tube defects and the spine. In: Nyberg DA, McGahan JP, Pretorius DH, Pilu G, eds. Diagnostic imaging of fetal anomalies. Philadelphia, PA: Lippincott Williams \& Wilkins, 2003;291-334.

21. Adamsbaum C, Moutard ML, Andre C, Merzoug V, Ferey S, Quere MP, et al. MRI of the fetal posterior fossa. Pediatr Radiol 2005;35:124-140.

22. Kolble N, Wisser J, Kurmanavicius J, Bolthauser E, Stallmach T, Huch $A$, et al. Dandy-walker malformation: prenatal diagnosis and outcome. Prenat Diagn 2000;20:318-327.

23. Maheshwari PR, Pungavkar SA, Narkhede P, Patkar DP. Images in radiology. Vein of Galen aneurysmal malformation: antenatal MRI. J Postgrad Med 2003;49:350-351.

24. Levine $D$, Barnes $P$, Korf $B$, Edelman R. Tuberous sclerosis in the fetus: second-trimester diagnosis of subependymal tubers with ultrafast MR imaging. AJR Am J Roentgenol 2000;175:1067-1069.

25. Blaas HG, Eik-Nes SH. Sonoembryology and early prenatal diagnosis of neural anomalies. Prenat Diagn 2009;29:312-325. 